\title{
Evaluation of Smear Layer Removal by Activation Ethylene Diamine Tetra Acetic Acid 17\% with Erbium Chromium: Yttrium Scandium Gallium Garnet and Diode Laser: Scanning Electron Microscopy
}

\author{
Chener S. Jameel ${ }^{\star}$, Nawfal A. Zakaria \\ Department of Conservative, Faculty of Dentistry, Tishk International University, Erbil, Kurdistan Region, Iraq
}

\author{
${ }^{*}$ Corresponding author: \\ Cheher S. Jameel, Faculty of \\ Dentistry, Tishk International \\ University, Erbil, Kurdistan \\ Region, Iraq. \\ E-mail: chenerakreyi@ \\ gmail.com
}

Received: 09 November 2019

Accepted: 24 February 2020

Published: 30 June 2020

\section{DOI}

10.25156/pti.v10n1y2020.pp103-109

\section{A B S T R A C T}

Background and Objectives: Activation of ethylene diamine tetra acetic acid (EDTA) with diode laser and Erbium Chromium: Yttrium Scandium Gallium Garnet ( $\mathrm{Er}, \mathrm{Cr}$ : YSGG) proposed as a promising adjuvant to conventional protocols but, its effectiveness has been seldom addressed. The purpose of this study was to evaluate the effect of laser-activated irrigations using the diode laser and the $\mathrm{Er}, \mathrm{Cr}$ : YSGG laser on removing smear layer (SL) from the root canal wall. Materials and Methods: SL was generated by preparing the root canals of extracted human teeth to a \#35/0.05 two shape instrument. The SL then received treatments of one of the following: Group 1, $5 \mathrm{ml}, 5.25 \% \mathrm{NaOCl}+5 \mathrm{ml}, 17 \%$ EDTA Each for $60 \mathrm{~s}$, Group $25 \mathrm{ml}$, Group 2, $5.25 \% \mathrm{NaOCl} 60 \mathrm{~s}+5 \mathrm{ml}$, 17\% EDTA $40 \mathrm{~s}+$ Diode laser $980 \mathrm{~nm} 20 \mathrm{~s} 5 \mathrm{ml}$, and Group 3, $5.25 \% \mathrm{NaOCl} 60 \mathrm{~s}+17 \%$ EDTA $35 \mathrm{~s}+\mathrm{Er}$, Cr: YSGG with RFT-2 tip for five cycles of $5 \mathrm{~s}$. Results: The activation of EDTA with diode laser $980 \mathrm{~nm}$ shows to be most effective in the SL in the apical and coronal third could be very useful adjutant in endodontic treatment due to its compactness.

Keywords: Diode laser $980 \mathrm{~nm}$; Ethylene diamine tetra acetic acid; Erbium chromium: Yttrium scandium gallium garnet laser; Smear layer; Sodium hypochlorite

\section{INTRODUCTION}

The mechanical instrumentation of root canals and the removal of dentin give rise to the formation of a thin smear layer (SL) covering the whole root canal wall. Many researchers believe that the SL should be considered deleterious. (Dederich et al., 1988; Mader et al., 1984; McComb and Smith, 1975) The SL prevents irrigants, medicaments, and filling materials from penetrating the dentinal tubules and even from contacting the canal wall, and it is considered to be responsible for the leakage between root canal wall and filling material (Sen et al., 1995). Consequently, many efforts have been made to remove the SL and debris and improve the adaptation of obturation materials to the root canal wall (Shokouhinejad et al., 2010).

Different irrigants and chelating agents, such as ethylene diamine tetra acetic acid (EDTA), citric acid, and phosphoric acid, have been recommended to remove the inorganic component of the SL, and sodium hypochlorite $(\mathrm{NaOCl})$ has been well known for its ability to remove of the organic component. (Pérez-Heredia et al., 2008) However, many studies have pointed the limited capacity of irrigants to reach all internal surfaces of the root canal structure. Therefore, more effective methods to clean and penetrate dentinal walls are necessary (DiVito et al., 2012).

Removal of the SL is usually performed by various endodontic irrigations (Çapar and Aydinbelge, 2014; Caron et al., 2010). The commonly used irrigants are sodium hypochlorite (NaOCl) and EDTA. (Lui et al., 2007; Moorer and Wesselink, 1982) $\mathrm{NaOCl}$ can remove the organic portion of the SL, and EDTA removes the inorganic portion. However, $\mathrm{NaOCl}$ irrigation, EDTA irrigation, or combined irrigation with $\mathrm{NaOCl}$ and EDTA have low efficacies of SL removal at the apical third of a root canal. However, they may effectively remove SL at the coronal and middle thirds of the canals (da Costa Lima et al., 2015; Mancini et al., 2009). This is because the canal is a kind of closed-end channel, which may cause gas entrainment and, as a result, produce a vapor lock effect during irrigant delivery. The apical vapor lock effect has an adverse impact on debridement efficacy (Tay et al., 2010). 
About laser application to endodontics, laser systems such as neodymium: Yttrium-aluminum-garnet $(\mathrm{Nd}$ : $\mathrm{YAG})$ and carbon dioxide (CO2) lasers have proved useful in cleaning and disinfecting the root canal and lateral dentinal tubules (Kimura et al., 2000; Moshonov et al., 1995). Following the development of the laser technique and device, the diode laser has gained increasing importance due to its compactness and low cost. The diode laser is recommended for endodontic treatment because its wavelength is within the infrared range, and thin and flexible fibers can be used. The previous report demonstrated the bactericidal effects of 810-nm wavelength (Moritz et al., 1997) and 980-nm wavelength diode lasers. (Gutknecht et al., 2004) However, to date, the potential application of $980-\mathrm{nm}$ wavelength diode laser in SL removal has seldom been addressed.

Mid-infrared lasers have been introduced to contribute to the conventional endodontic therapy for their capacity to eliminate microorganisms and increasing dentinal permeability by SL removal (Aranha et al., 2005; Kimura et al., 2000; Schoop et al., 2007, 2004). Erbium Chromium: Yttrium Scandium Gallium Garnet (Er, Cr: YSGG laser has a $2980 \mathrm{~nm}$ wavelength) has a high affinity for water absorption and hydroxyapatite. Numerous studies demonstrated the capacity of Er, Cr: YSGG laser to remove debris SL after biomechanical instrumentation (Yamazaki et al., 2001) and do not lead to carbonization or melting of tissue (Ishizaki et al., 2004; Yamazaki et al., 2001). This laser employed a laser beam pulsed source transmitted by a sapphire tip with air/water spray. When the interaction of laser energy with water and the target tissue occurred, this generated a tissue cut, creating a hydrokinetic system the biological materials through a high-speed water spray through a process called the hydrokinetic debridement. During laser application, heating, and vaporization of water occur which create a high pressure steam that lead a micro-explosion of the dental tissues below its fusion point (Rizoiu et al., 1996). Water vaporization into the mineral substrate leads to an explosion of the surrounding material factually outward (Li et al., 1992). Due to limited study have discussed the efficiency of activation of EDTA with $980 \mathrm{~nm}$ diode laser and Er, Cr: YSGG laser on SL removal in the specified third of the root canal wall.

\section{MATERIALS AND METHODS}

For this experimental study, 50 extracted permanent single-rooted human teeth used. All the selected teeth were single canaled, complete closed apex, and round-shaped canal when viewed cross-sectionally and no previous canal treatment. Exclusion criteria include the presence of caries, calculus, open apex, radicular resorption, radicular fractures, and more than one canal.
Each tooth was examined with periapical radiograph buccolingually and mesiodistally with a digital X-ray sensor (Vatech-Classic 1.5 Sensor) and portable X-ray source (Vatech EzRay Air portable) to ensure the inclusion criteria.

The roots were imbedded in condensation silicone Optosil Comfort (Kulzer GmbH, Germany). Up to 3-4 mm of the most coronal part of the root kept exposed molded within $25 \mathrm{~mm}$ PVC pipe, in which the inner surface was coated with a Universal adhesive (Kulzer GmbH, Germany) to enhance condensation silicone retention. Moreover, the roots apical foramen sealed with plastic dispensed from plastic heat gun so as create a closed system and prevent the extrusion of irrigant beyond anatomical apex as suggested by Tay et al. 2010, Parente et al. 2010 (Parente et al., 2010; Tay et al., 2010).

Then, after the embedding the roots, the assembly was mount to table mount in an upright position where the root was embedded in the assembly where the anatomical apex was facing the floor and the assembly to be perpendicular to the floor with the aid of spirit level in a vertical and horizontal plane.

Before the grouping, the teeth were prepared with nickeltitanium heat-treated T-wire, 2Shape TS1 \#25 4\%, TS2 \#25 6\%, and size 35 6\% (COLTENE MircroMega, France). Files were loaded inside the canal sequentially, which all the canal patency with K-file size 10 (access Maillefer Dentsply, Switzerland) were obtained before starting the rotary preparation in the working length determination using phase and prepared with the endodontic rotary device from ENDO-MATE DT (NAKANISHIN, INC., JAPAN). According to MM-ENDObook ("MMEndoBook," n.d.), the manual after obtaining the patency with k-file \#10 the One G \#14 3\% to provide glide path inserted into the canal at full working length with setting speed of rotation $400 \mathrm{rpm}$ Torque: $1.2 \mathrm{~N} . \mathrm{cm}$, and then patency was verified again with k-file \#10. The TS1, TS2 and file size \#35 taper 6\% inserted into the canal with progressive movement in three waves (3 up-and-down motions) at the setting of the speed of rotation: 400 rpm and torque: $2.6 \mathrm{~N} . \mathrm{cm}$ through the rotary handpiece which was held to custom fabricated holder attached to the vertical spindle of the surveyor and the teeth assembly were fixed to the surveyor clamp with the aid of custom made gypsum block introduced in the canal. Remove the file from the root canal, clean the root canals were cleaned and irrigated. Then continue the progressive downward movement. Moreover, during all preparation procedures, irrigation was performed with a Navitip 31 gauge (Ultradent Incorporation products, USA). Vented needle coupled to the $5 \mathrm{~mL}$ disposable syringe after using each file (manual or roundabout), the canals were 
irrigated with $1 \mathrm{~mL}$ of $5.25 \% \mathrm{NaOCl}$ (TechnoDent Co. Ltd., Russia), the needle was first placed to $1 \mathrm{~mm}$ short of the working length and was then moved back and forth (Wang et al., 2017).

The samples were randomly divided into three group hand each group individual will be receiving treatment as follows;

\section{Group One}

In the first group, samples $(n=10)$ were irrigated with $5 \mathrm{ml} 5.25 \% \mathrm{NaOCL}$ for total $60 \mathrm{~s}$ and followed by $5 \mathrm{ml}$ $17 \%$ EDTA for total $60 \mathrm{~s}$ in which both irrigants were reloaded into the canal at portion of $2.5 \mathrm{ml}$ each separated by interval of $30 \mathrm{~s}$, a $10 \mathrm{ml}$ of distilled water was used in between the irrigations for deactivation of effect of irrigants on each other.

\section{Group Two}

In the third group, samples $(n=10)$ were irrigated with $5 \mathrm{ml} \mathrm{5.25 \%} \mathrm{NaOCL}$ for total $60 \mathrm{~s}$ and followed by $5 \mathrm{ml}$ $17 \%$ EDTA for total $40 \mathrm{~s}$, in which both irrigants were reloaded in into the canal at portion of $2.5 \mathrm{ml}$ each separated by interval of $30 \mathrm{~s}$, a $10 \mathrm{ml}$ of distilled water was used in between the irrigations for deactivation of effect of irrigants on each other, then EDTA activated with a fiber tip $\left(\varnothing=300 \_1 \mathrm{~m}\right)$ at $2 \mathrm{~W}$ using the pulsed mode (10 Ton MS/Toff $10 \mathrm{MS}$ ) of the diode laser (980 $\mathrm{nm}$, Doctor smile, simpler) for $20 \mathrm{~s}$. The specimens to be then irrigated for $40 \mathrm{sec}$ with $4 \mathrm{~mL} \mathrm{17 \%} \mathrm{EDTA} \mathrm{as} \mathrm{a}$ final flush as suggested by (Koçak et al., 2015).

\section{Group Three}

In the fifth group, samples $(n=10)$ were irrigated with $5 \mathrm{ml} 5.25 \% \mathrm{NaOCL}$ for total $60 \mathrm{~s}$ and followed by $5 \mathrm{ml}$ $17 \%$ EDTA for total $35 \mathrm{~s}$, in which both irrigants were reloaded in into the canal at portion of $2.5 \mathrm{ml}$ each separated by interval of $30 \mathrm{~s}$ a $10 \mathrm{ml}$ of distilled water was used in between the irrigations for deactivation of effect of irrigants on each other, then EDTA activated with Er,Cr:YSGG laser with a $2.780 \mathrm{~nm}$ wavelength and a "Radial Firing Tips" RFT-2, with a $275 \mu$ diameter, making helicoidal movements from apical to coronal. A laser tip will be introduced to $1 \mathrm{~mm}$ less than the working length; this is $11 \mathrm{~mm}$. The activation of the laser was repeated for five cycles of $5 \mathrm{~s}$ each, with a break of 20 s between each cycle. Er,Cr:YSGG laser used following this parameter: $1.25 \mathrm{~W}, 50 \mathrm{~Hz}$, and $24 \%$ air and $30 \%$ water.

Longitudinal grooves were carved onto the facial and lingual root surfaces using a low-speed diamond disk, without entering the inner parts of the canals. Then, it was split into two parts with an acuminate chisel and hammer.
The spited roots were dehydrated with ethyl alcohol $(30 \%$, $50 \%, 70 \%, 80 \%, 90 \%$, and $100 \%$ for 10 min each), dried in a desiccator for $24 \mathrm{~h}$, and the split inner roots surface were metalized with gold by direct-current chemical vapor deposition.

The samples were exposed to a $20 \mathrm{kv}$ electron gun to provide the morphology of the inner surface of the sample. Moreover, sketch was sent to the operator determining the microscopic field under scanning electron microscopy. For each specimen (12 $\mathrm{mm}$ in length), the canal was divided into the coronal, middle, and apical thirds with equal lengths of $4 \mathrm{~mm}$. Then, five microscopic fields were taken at the center of each designated microscopic field of each third at a magnification of $\times 300, \times 600$, $\times 1000, \times 3000$, and $\times 6000$.

Then, specimens will be coded based on the final irrigation protocol. Blindly, three investigators are going to score the presence or absence of SL on the surface of the root canal or in the dentinal tubules at the coronal, middle, and apical portion of each canal according to the following criteria suggested by Torabinejad et al (Torabinejad et al., 2002):

- Score 1: No SL. No SL on the surface of the root canals; all tubules were clean and open

- Score 2: Moderate SL. No SL on the surface of the root canal, but tubules contained debris

- Score 3: Heavy SL. The SL covered the root canal surface and the tubules.

\section{Statistical Analysis}

Descriptive statistics is a critical stage for any study to start with interpreting the nature of the data. However, not every potential side of the data can be observed. Thirty observations were used to evaluate the amount of SL produced while providing treatment. Since we collect only three values where each represents the different result, thus we mainly focus on mode seeking to the most repeated value. Table 1 illustrates the descriptive statistics for Group 1(G1), Group 2 (G2), and Group 3 (G3).

Table 1: Descriptive statistics for G1, G2, and G5

\begin{tabular}{lllccc}
\hline Variables & Canal Area & N & Mode & Mean & Standard deviation \\
\hline G1 & Apical & 10 & 3 & 2.500 & 0.707 \\
& Middle & 10 & 1 & 1.400 & 0.699 \\
\multirow{4}{*}{ G2 } & Coronal & 10 & 2 & 1.800 & 0.422 \\
& Apical & 10 & 1 & 1.600 & 0.699 \\
& Middle & 10 & 2 & 1.600 & 0.516 \\
G3 & Coronal & 10 & 1 & 1.400 & 0.516 \\
& Apical & 10 & 2 & 2.400 & 0.516 \\
& Middle & 10 & 2 & 2.100 & 0.316 \\
& Coronal & 10 & 2 & 2.000 & 0.000 \\
\hline
\end{tabular}


Based on the result at the apical part of G1, the most repeatable value recorded was three with a mean value 2.50 , which means a very heavy SL existed where both the root canal surface and the tubules were covered. Fortunately, no SL was detected at middle area of the teeth with a mean value of 1.400 (quite close to 1). However, the coronal part of teeth seemed to have a moderate SL on tubules. For G2's results, at both parts of the canals apical and coronal, the most repeated value was reported in 1 (means zero SL amount) with mean values 1.600 and 1.400 correspondingly, with an only moderate level of SL in middle area with mean value 1.600. Likewise, in G3, all parts of the teeth on our sample appeared to have debris in tubules of the teeth only called a moderate SL where all modes were two with mean values $(2.400,2.100$, and 2) for Apical, Middle, and Coronal, respectively.

Consequently, through the descriptive statistics G2 showed better performance toward occurring SL type, and it, of course, differs with both G1 and G3.

According to Table 2, moderate SL level was seen more than other levels in G3 at all teeth parts with 100\% for Coronal, followed by Middle with 90\% and then 60\% at Apical, and the remaining percentage corresponded to heave SL type with $10 \%$ and $40 \%$ correspondingly. On the other hand, the levels of SL in G1 are different and at Apical $60 \%$ of the cases were found to be covered with debris on the root canal surface as well as the tubules, whereas $30 \%$ of them were enclosed with debris at the moderate level and only 10\% had no SL. In contrast, the type of SL coverage at the middle area was identified the other way around with $70 \%$ of cases had no SL, while only $10 \%$ had heavy SL on the root surface as well as tubules. At the coronal location, $80 \%$ of teeth were recorded to be covered moderately and $20 \%$ with no SL type coded.

Regarding G2 results, though the whole length of the canal minimal amount of heavy SL noticed with only 10\% at the apical location. It is worth saying that comparing to the other groups G1 and G5, the percentage of verifying

Table 2: Frequency distribution of smear layer types in each group's area

\begin{tabular}{|c|c|c|c|c|c|c|c|}
\hline \multirow[t]{2}{*}{ Variables } & \multirow[t]{2}{*}{ Group } & \multicolumn{2}{|c|}{1} & \multicolumn{2}{|c|}{2} & \multicolumn{2}{|c|}{3} \\
\hline & & $n$ & $\%$ & $n$ & $\%$ & $n$ & $\%$ \\
\hline \multirow[t]{3}{*}{ G1 } & Apical & 1 & 10 & 3 & 30 & 6 & 60 \\
\hline & Middle & 7 & 70 & 2 & 20 & 1 & 10 \\
\hline & Coronal & 2 & 20 & 8 & 80 & 0 & 0 \\
\hline \multirow[t]{3}{*}{ G2 } & Apical & 5 & 50 & 4 & 40 & 1 & 10 \\
\hline & Middle & 4 & 40 & 6 & 60 & 0 & 0 \\
\hline & Coronal & 6 & 60 & 4 & 40 & 0 & 0 \\
\hline \multirow[t]{3}{*}{ G2 } & Apical & 0 & 0 & 6 & 60 & 4 & 40 \\
\hline & Middle & 0 & 0 & 9 & 90 & 1 & 10 \\
\hline & Coronal & 0 & 0 & 10 & 100 & 0 & 0 \\
\hline
\end{tabular}

from zero SL of debris at the root of the surface as well as in tubules. About $60 \%$ of the cases were recorded with no SL in Coronal, followed by Apical with 50\%, then 40\% in the Middle area, and the remaining was for a moderate level of SL. To sum up, there is a clear difference between G2 and G3, and based on the data, G2 performed better than both groups in general.

In the light of comparison between the area within groups and with groups, there may not be any significant difference at G3. Still, there is substantial difference in mean values of G1 and G3 between the areas. In the next section, we will apply statistical tests to examine the differences. Instead of ANOVA test to be used to compare more than two groups mean values, the Kruskal-Wallis $\mathrm{H}$ test used since data did not meet the normality assumption, and for pairwise comparison, the Mann-Whitney U-test conducted.

Table 3 shows a statistically significant difference between G1, G2, and G3 for all three areas due to having (0.015 and 0.010$) P<0.05$ using the Kruskal-Wallis $\mathrm{H}$ test. Thus, we reject the null hypothesis, which means that SL types have occurred with different effectiveness at the locations of our teeth sample regarding the usage of materials and tools. By conducting post hoc test (pairwise comparison) with Mann-Whitney U-test, we could figure out that G2 was statistically significant with G1 and G3 at Apical canal location, despite showing similar effects of both G1 and G3 materials on the teeth, there was significant difference at middle area. Furthermore, at coronal the considerable difference occurred at coronal between G2 and G3, and the same effect was found between G1 and G3. The most similarities of produced SL types were between G1 and G3. It is also worth mentioning that more SL can be seen on teeth where G3 had been applied on, while the lowest is for $\mathrm{G} 2$.

In this phase, we implemented the comparison test within groups according to the areas specified. Table 4 displays the result of Kruskal-Wallis and Mann-Whitney within the groups. Significant differences in the mean value of the amount SL were produced from one location to another one in G1, and the below result indicated that apical differed with the middle and coronal area. In contrast, no difference highlighted between middle and coronal. Unlike

Table 3: Kruskal-Wallis H test of each area between G1, G3, and G5

\begin{tabular}{llll}
\hline Area & Apical & Middle & Coronal \\
\hline Kruskal-Wallis H & 8.373 & 8.359 & 9.227 \\
$P$-Value & 0.015 & 0.015 & 0.010 \\
Pairwise & Sig. Difference & Sig. & Sig. \\
comparison test & G3 versus. G1 & Difference & Difference G3 \\
$\begin{array}{l}\text { (Mann Whitney } \\
\text { U-test) }\end{array}$ & and G5 & G5 versus G1 & versus G5 \\
& & and G3 & \\
\hline
\end{tabular}




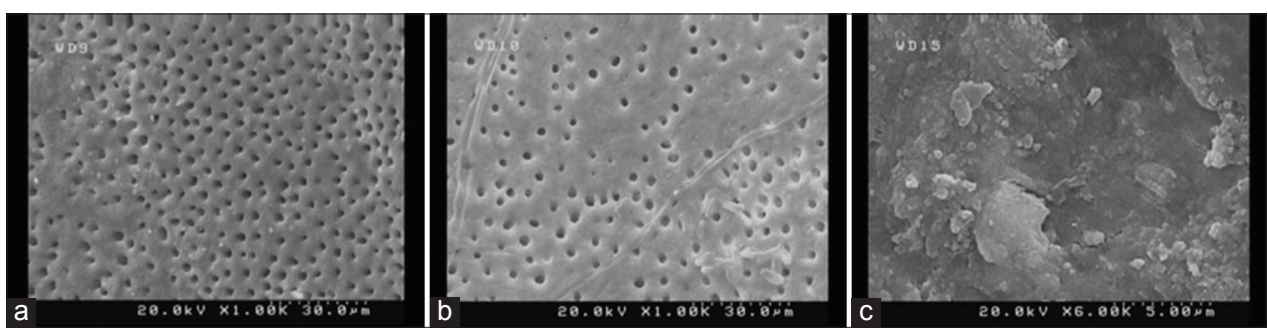

Figure 1: Illustrative scanning electron microscopic image for scoring the smear layer (a) score 1, (b) score 2, and (c) score 3

Table 4: Kruskal-Wallis and Mann-Whitney test between areas for G1, G3, and G5

\begin{tabular}{lccll}
\hline Variables & \multicolumn{2}{c}{ Kruskal-Wallis H } & & Pairwise comparison \\
\cline { 2 - 3 } & Test value & $P$-value & & Result \\
\hline G1 & 10.645 & 0.005 & & Apical versus middle and coronal \\
G3 & 0.763 & 0.683 & & No significant occurred \\
G5 & 6.032 & 0.049 & & Apical versus coronal \\
\hline
\end{tabular}

to G1, G3 only apical and coronal differed regarding SL availability. Furthermore, G2 in the meanwhile revealed no significant difference between the areas which means that the same influence in terms of SL level enhancement (no SL, moderate "no surface but only tubules covered with SL," heave SL "Root canal surface and tubules were covered with debris") since the $P$-value $(0.683)$ is higher than 0.05 .

\section{DISCUSSION}

Many authors have been studying SL removal because its presence in the dentinal wall affects the root canal system seal.

The SL reduction by $\mathrm{NaOCl} 5.25 \%$ + EDTA $17 \%$ has been proved to be effective by many authors (Goldman et al., 1981; Gutmann et al., 1994). In the current study, the samples that were irrigated by $\mathrm{NaOCl}+\mathrm{EDTA}$ consecutively aided in reduction of SL from the coronal third of the canal walls and had eliminated SL in the middle third while in the apical third heavy SL existed at the apical third relatively comparative results obtained by study carried out by Patil et al., 2018. Moreover, this is a heavy SL in the apical third of the canal samples that treated by $\mathrm{NaOCl}+\mathrm{EDTA}$ may be attributed to the small size of apical third and the apical vapor lock effect (Gutknecht et al., 2004) which considered as an obstacle that preventing the circulation and action of the irrigation.

Finally, laser therapy acquired great attention due to its promising application and in endodontic specifically; great attention directed toward laser role in SL removal.

Diode laser $980 \mathrm{~nm}$ is very interesting because these are close to harmonics for water absorption and more strongly absorbed than the other available near-infrared wavelength (Hmud et al., 2010). In the present study, the samples were treated with the EDTA 17\% agitated by diode laser $980 \mathrm{~nm}$, showed minimal amount of SL in the apical and coronal third and statistically more significant than $\mathrm{NaOCl}+\mathrm{EDTA}$ and EDTA+Er;Cr;YSGG while in the middle third it was relatively compared with sample treated with $\mathrm{NaOCl}+$ EDTA and less effective in SL removal than samples treated with EDTA+Er; Cr: YSGG.

The inclusion of Er; Cr: YSGG laser in endodontics attributed to present new approach since Er; Cr: YSGG is medium infrared laser that is well absorbed by the water and consequently has a superficial ablative effect that leads to SL removal in addition to decontamination of the root canal surface. Moreover, in the present study, the employment of EDTA+Er; Cr: YSGG laser did not show statistical difference in the apical and coronal third when compared to the samples treated by $\mathrm{NaOCl}+\mathrm{EDTA}$, while in the middle third it was more effective in SL removal than the group treated in SL removal than samples treated with $\mathrm{NaOCl}+\mathrm{EDTA}$ and EDTA+Diode laser. The similar result was obtained by a study carried out by Montero-Miralles et al., 2018, and this could be due to large size of the canals as they were enlarged to size \#35 6\% and he fiber had more space to move (George et al., 2008).

Many other authors have concluded that utilization of Er; Cr: YSGG laser+EDTA is effective in SL removal, but did not specify the studied thirds (Ishizaki et al., 2004; Yamazaki et al., 2001).

\section{CONCLUSION}

Based on the results of this study, root canal treated with EDTA agitation with diode laser showed to be most effective in SL removal in the apical and coronal third. Where $\mathrm{NaOCl}+$ EDTA and EDTA agitation with Er; $\mathrm{Cr}$ : YSGG laser showed similar results in the apical and coronal third except EDTA agitation with Er; Cr: YSGG laser was most effective when compared with EDTA agitation with diode laser and $\mathrm{NaOCl}+$ EDTA. 


\section{ACKNOWLEDGMENT}

The authors wish to thank Dr. Botan Abdullah, Dr. Omer Sherwan and Dr. Jwana Majid for assessment and scoring of the SEM images.

\section{CONFLICTS OF INTEREST}

The authors declare that there are no relevant financial interests about the submitted manuscript within the past 5 years and for the foreseeable future.

\section{ETHICAL CONSIDERATIONS}

The research carried out under conventional ethical considerations.

\section{FINANCIAL DISCLOSURE}

The authors declare that there are no relevant financial conflicts about the submitted manuscript within the past 5 years and for the foreseeable future.

\section{FUNDING/SUPPORT}

This research funded by researcher only.

\section{REFERENCES}

Aranha, A., F. B. Domingues, O. V. Franco, N. Gutknecht and C. Eduardo. 2005. Effects of Er:YAG and Nd:YAG lasers on dentin permeability in root surfaces: A preliminary in vitro study. Photomed. Laser Surg. 23(5): 504-508.

Çapar, I. D. and H. A. Aydinbelge. 2014. Effectiveness of various irrigation activation protocols and the self-adjusting file system on smear layer and debris removal. Scanning. 36: 640-647.

Caron, G., K. Nham, F. Bronnec and P. Machtou. 2010. Effectiveness of different final irrigant activation protocols on smear layer removal in curved canals. J. Endod. 36: 1361-1366.

da Costa Lima, G. A., C. M. Aguiar, A. C. Câmara, L. C. Alves, F. A. B. Dos Santos and A. E. do Nascimento. 2015. Comparison of smear layer removal using the Nd:YAG laser, ultrasound, protaper universal system, and canalbrush methods: An in vitro study. J. Endod. 41: 400-404.

Dederich, D., K. L. Zakariasen and J. Tulip. 1988. An in-vitro quantitative analysis of changes in root canal wall dentin due to pulsed neodymium-yttrium-aluminium-garnet laser irradiation. Laser Life Sci. 2: 39-51.

DiVito, E., O. A. Peters and G. Olivi. 2012. Effectiveness of the erbium:YAG laser and new design radial and stripped tips in removing the smear layer after root canal instrumentation. Lasers Med. Sci. 27: 273-280.

George, R., I. A. Meyers and L. J. Walsh. 2008. Laser activation of endodontic irrigants with improved conical laser fiber tips for removing smear layer in the apical third of the root canal. J.
Endod. 34: 1524-1527.

Goldman, L. B., M. Goldman, J. H. Kronman and P. S. Lin. 1981. The efficacy of several irrigating solutions for endodontics: A scanning electron microscopic study. Oral Surg. Oral Med. Oral Pathol. 52: 197-204.

Gutknecht, N., R. Franzen, M. Schippers and F. Lampert. 2004. Bactericidal effect of a $980-\mathrm{nm}$ diode laser in the root canal wall dentin of bovine teeth. J. Clin. Laser Med. Surg. 22: 9-13.

Gutmann, J. L., W. P. Saunders, L. Nguyen, I. Y. Guo and E. M. Saunders. 1994. Ultrasonic root-end preparation. Part 1. SEM analysis. Int. Endod. J. 27: 318-324.

Hmud, R., W. A. Kahler, R. George and L. J. Walsh. 2010. Cavitational effects in aqueous endodontic irrigants generated by nearinfrared lasers. J. Endod. 36: 275-278.

Ishizaki, N. T., K. Matsumoto, Y. Kimura, X.Wang, J. I. Kinoshita, S. M.Okano and J. A. Jayawardena. 2004. Thermographical and morphological studies of Er,Cr:YSGG laser irradiation on root canal walls. Photomed. Laser Surg. 22: 291-297.

Kimura, Y., P. Wilder-Smith and K. Matsumoto. 2000. Lasers in endodontics: A review. Int. Endod. J. 33: 173-185

Koçak, S., E. Çiçek, B. C. Sağlam, M. M. Koçak and S. A. Türker. 2015. Influence of diode laser application on the efficiency of QMiX and EDTA solutions in removing smear layer. Photomed. Laser Surg. 33: 564-567.

Li, Z. Z., J. E. Code and W. P. Van De Merwe. 1992. Er:YAG laser ablation of enamel and dentin of human teeth: Determination of ablation rates at various fluences and pulse repetition rates. Lasers Surg. Med. 12: 625-630.

Lui, J. N., H. G. Kuah and N. N. Chen. 2007. Effect of EDTA with and without surfactants or ultrasonics on removal of smear layer. J. Endod. 33: 472-475.

Mader, C. L., J. C. Baumgartner and D. D Peters. 1984. Scanning electron microscopic investigation of the smeared layer on root canal walls. J. Endod. 10: 477-483.

Mancini, M., E. Armellin, A. Casaglia, L. Cerroni and L. Cianconi. 2009. A comparative study of smear layer removal and erosion in apical intraradicular dentine with three irrigating solutions: A scanning electron microscopy evaluation. J. Endod. 35: 900-903.

McComb, D. and D. C. Smith. 1975. A preliminary scanning electron microscopic study of root canals after endodontic procedures. J. Endod. 1: 238-242.

MM-EndoBook. n.d. Micro-Mega SA. Available from: https://www. micro-mega.com $/ \mathrm{mm}$-endobook?lang=en. [Last accessed on 2019 Feb 23].

Montero-Miralles, P., D. Torres-Lagares, J. J. Segura-Egea, M. Á. Serrera-Figallo, J. L. Gutierrez-Perez and G. Castillo-Dali. 2018. Comparative study of debris and smear layer removal with EDTA and Er,Cr:YSGG laser. J. Clin. Exp. Dent. 10: e598-e602.

Moorer, W. R. and P. R. Wesselink. 1982. Factors promoting the tissue dissolving capability of sodium hypochlorite. Int. Endod. J. 15: 187-196.

Moritz, A., N. Gutknecht, U. Schoop, K. Goharkhay, O. Doertbudak and W. Sperr. 1997. Irradiation of infected root canals with a diode laser in vivo: Results of microbiological examinations. Lasers Surg. Med. 21: 221-226.

Moshonov, J., A. Sion, J. Kasirer, I. Rotstein and A. Stabholz. 1995. Efficacy of argon laser irradiation in removing intracanal debris. Oral Surg. Oral Med. Oral Pathol. Oral Radiol. Endodontol. 79: 221-225.

Parente, J. M., R. J. Loushine, L. Susin, L. Gu, S. W. Looney, R. N. Weller, D. H. Pashley and F. R. Tay. 2010. Root canal debridement using manual dynamic agitation or the EndoVac for final irrigation in 
a closed system and an open system: Effect of apical negative pressure on irrigation. Int. Endod. J. 43: 1001-1012.

Patil, P. H., M. N. Gulve, S. J. Kolhe, R. M. Samuel and G. B. Aher. 2018. Efficacy of new irrigating solution on smear layer removal in apical third of root canal: A scanning electron microscope study. J. Conserv. Dent. JCD. 21: 190-193.

Pérez-Heredia, M., C. M. Ferrer-Luque, M. P. González-Rodríguez, F. J. Martín-Peinado and S. González-López. 2008. Decalcifying effect of $15 \%$ EDTA, $15 \%$ citric acid, $5 \%$ phosphoric acid and $2.5 \%$ sodium hypochlorite on root canal dentine. Int. Endod. J. 41: 418-423.

Rizoiu, I. M., A. I. Kimmel and L. R. Eversole. 1996. Effects of an Er, Cr:YSGG laser on canine oral hard tissues. In: Laser Applications in Medicine and Dentistry. Presented at the Laser Applications in Medicine and Dentistry, International Society for Optics and Photonics, United States. p74-84.

Schoop, U., K. Goharkhay, J. Klimscha, M. Zagler, J. Wernisch, A. Georgopoulos, W. Sperr and A. Moritz. 2007. The use of the erbium, chromium:yttrium-scandium-gallium-garnet laser in endodontic treatment: The results of an in vitro study. J. Am. Dent. Assoc. 138: 949-955.

Schoop, U., W. Kluger, A. Moritz, N. Nedjelik, A. Georgopoulos and W. Sperr. 2004. Bactericidal effect of different laser systems in the deep layers of dentin. Lasers Surg. Med. 35: 111-116.

Sen, B. H., P. R. Wesselink and M. Türkün. 1995. The smear layer: A phenomenon in root canal therapy. Int. Endod. J. 28: 141-148.

Shokouhinejad, N., M. R. Sharifian, M. Aligholi, H. Assadian, R. K. Tabor and M. H. Nekoofar. 2010. The sealing ability of resilon and gutta-parcha following different smear layer removal methods: An ex vivo study. Oral Surg. Oral Med. Oral Pathol. Oral Radiol. Endod. 110: e45-49.

Tay, F. R., L. S. Gu, G. J. Schoeffel, C. Wimmer, L. Susin, K. Zhang, S. N. Arun, J. Kim, S. W. Looney and D. H. Pashley. 2010. Effect of vapor lock on root canal debridement by using a side-vented needle for positive-pressure irrigant delivery. J. Endod. 36: 745-750.

Torabinejad, M., R. Handysides, A. A. Khademi and L. K. Bakland. 2002. Clinical implications of the smear layer in endodontics: $A$ review. Oral Surg. Oral Med. Oral Pathol. Oral Radiol. Endod. 94: 658-666.

Wang, X., X. Cheng, B. Liu, X. Liu, Q. Yu and W. He. 2017. Effect of laser-activated irrigations on smear layer removal from the root canal wall. Photomed. Laser Surg. 35: 688-694.

Yamazaki, R., C. Goya, D. G. Yu, Y. Kimura and K. Matsumoto. 2001. Effects of erbium,chromium:YSGG laser irradiation on root canal walls: A scanning electron microscopic and thermographic study. J. Endod. 27: 9-12. 